\title{
APLIKASI MONITORING PERSEDIAAN DENGAN METODE USER CENTER DESIGN PADA PT. SAHABAT JAYA CEMERLANG
}

\author{
Rahel Junita \\ Fakultas Ekonomi dan Bisnis, Universitas Sumatera Utara \\ rachel.junita0306@gmail.com
}

\begin{abstract}
The development of increasingly rapid and modern technology has an influence on the way personal and organizational work. Especially in the business world, technological developments make it easier for business people to make more practical ways of working. In the business world, technology can be used as a tool to monitor activities that occur in the business including sales transactions and monitoring of available merchandise stocks, so the formulation of the problem in this proposal is how to make an application for monitoring beverage product data in an web-based warehouse effectively by implementing User Centered Design method. So with the monitoring of the stock of goods in the warehouse, it makes it easier for warehouse heads and managers to monitor or find out the stock of goods, incoming and outgoing goods effectively in real time. The system built can make it easy for warehouse staff to issue and enter goods using barcode scans without having to record goods manually.
\end{abstract}

Keywords: monitoring, stock, web application.

\section{PENDAHULUAN}

Pengelolaan persediaan berbasis aplikasi yang semakin pesat dan modern memberikan pengaruh dari cara kerja personal maupun organisasi. Dalam dunia bisnis teknologi dapat digunakan sebagai alat untuk memonitor kegiatan-kegiatan yang terjadi dalam bisnis diantaranya transaksi penjualan dan monitoring stok barang dagangan yang tersedia. PT. Sahabat Jaya Cemerlang merupakan pelaku bisnis atau perusahaan distributor penjualan macam-macam jenis minuman keras golongan A di kota Medan. Proses pencatatan barang saat ini pada PT. Sahabat Jaya Cemerlang terjadi dua kali, pencatatan secara manual di gudang dan selanjutnya proses pengimputan data ke komputer. Sehingga proses pencatatannya tentu akan membutuhkan waktu yang lama dan besar kemungkinan mengalami kesalahan karna adanya human eror. Hal tersebut menjadi pertimbangan penulis untuk membangun aplikasi monitoring yang berfungsi untuk pencatatan, pemantauan, sampai pengolahan data produk minuman yang ada pada gudang PT. Sahabat Jaya Cemerlang. Persediaan (inventory) adalah stok dari suatu item atau sumber daya, bahan, material yang disimpan dan disediakan oleh suatu perusahaan untuk mendukung proses bisnisnya dan memenuhi permintaan dari konsumen atau pelanggan setiap waktu. Pengendalian persediaan (stock control) adalah usaha yang dilakukan oleh perusahaan dalam penyediaan barang-barang yang dibutuhkan untuk proses produksi agar terpenuhi secara optimal sehingga proses produksi berjalan dengan lancar dan mengurangi adanya resiko yang akan terjadi seperti kekurangan barang serta perusahaan dapat memperoleh biaya persediaan sekecilkecilnya yang akan menguntungkan perusahaan. Pengendalian persediaan harus dilakukan dengan seimbang. Jika persediaan terlalu besar (over stock) maka beban-beban biaya untuk menyimpan dan menjaga persediaan di dalam gudang akan tinggi sehingga hal ini akan menyebabkan pemborosan. Sebaliknya, jika persediaan terlalu kecil atau dapat dikatakan kurangnya persediaan (out of stock) maka waktu pengiriman barang yang telah disepakati bersama antara perusahaan dengan konsumen akan menjadi terhambat. Keterlambatan waktu pengiriman akan membuat konsumen beralih ke perusahaan lain dalam melakukan pembelian barang. Maka dilakukan monitoring bertujuan untuk proses pengumpulan dan analisis informasi berdasarkan indikator yang ditetapkan secara sistematis dan kontinu tentang kegiatan program sehingga dapat dilakukan tindakan koreksi untuk penyempurnaan program kegiatan 
itu selanjutnya. Dalam mengaplikasikannya dibutuhkan pengelolaan basis data yang berbasis computer sehingga kumpulan tabel yang saling berelasi, relasi tersebut bisa ditunjukkan dengan kunci dari tiap tabel yang ada.Satu database menunjukkan satu lingkup perusahaan atau instansi.

Maka diperlukan sebuah aplikasi dalam bentuk program computer siap pakai yang dapat digunakan untuk menjalankan perintah-perintah dari pengguna aplikasi tersebut dengan tujuan mendapatkan hasil yang lebih akurat sesuai dengan tujuan pembuatan aplikasi tersebut. Saat ini telah banyak diterapkan pada aplikasi yang berbasis web. Yaitu sistem operasi bersifat open source berbasis Linux dirancang untuk perangkat seluler layar sentuh seperti telepon pintar dan komputer tablet.

Dalam perancangan ini menggunakan model Unified Modelling Language (UML) sebagai sebuah "bahasa" yang telah menjadi standar dalam industri untuk visualisasi, merancang dan mendokumentasikan sistem peranti lunak.UML menawarkan sebuah standar untuk merancang model sebuah sistem. Kemudian menggunakan JavaScript Object Notation(JSON) yaitu format pertukaran data yang ringan, mudah dibaca dan ditulis oleh manusia, serta mudah diterjemahkan dan dibuat (generate) oleh komputer. Menggunakan bahasa pemrograman java dan database My Stuctured Query Language (MySQL) sebagai sistem manajemen database SQL yang bersifat Open Source dan paling populer saat ini.Sistem Database MySQL mendukung beberapa fitur seperti multithreaded, multi-user, dan SQL database managemen sistem (DBMS).

\section{METODE PENELITIAN}

Metode penelitian adalah cara pokok yang dipergunakan oleh peneliti dalam mencapai tujuan serta menentukan jawaban dari masalah yang sedang diajukan. Dalam penelitian berhubungan sangat dengan prosedur, rancangan, alat penelitian yang digunakan untuk melaksanaan penelitian tersebut. Langkah-langkah/algoritma proses dalam penelitian ini berjalan sesuai dengan alur yang bersifat logis. Bertujuan agar memberikan petunjuk yang jelas, ringkas, teratur dan sistematis. Metode yang digunakan dapat dilihat pada Gambar 1. Dalam hal ini Peneliti mempergunakan metode water fall dalam mengerjakan penelitian ini dikarenakan penelitian ini menggunakan satu objek penelitian yaitu pembangunan Aplikasi sistem informasi inventory berbasis web pada PT. Sahabat Jaya Cemerlang dan hasilnya berupa suatu pemecahan masalah dari objek penelitian tersebut yang tidak berbentuk perhitungan atau statistik.

Sedangkan untuk pengumpulan data, peneliti menggunakan metode Observasi dengan cara mengamati secara langsung terhadap aktivitas kerja PT. Sahabat Jaya Cemerlang khususnya bagian gudang. Peneliti melakukan kegiatan observasi secara langsung ke gudang dan kedua melakukan wawancara dilakukan dengan mengadakan tanya jawab secara langsung pada bagian-bagian. Sedangkan untuk pengembangan sistem, peneliti menggunakan metode WDLC (Website Development Life Cycle). Adapun tahapan-tahapan dalam model WDLC yaitu (1) Data Collection, (2) Sistem Analisis (3) Layout \& Design. (4) Development. (5) Testing. (6) Implementation..

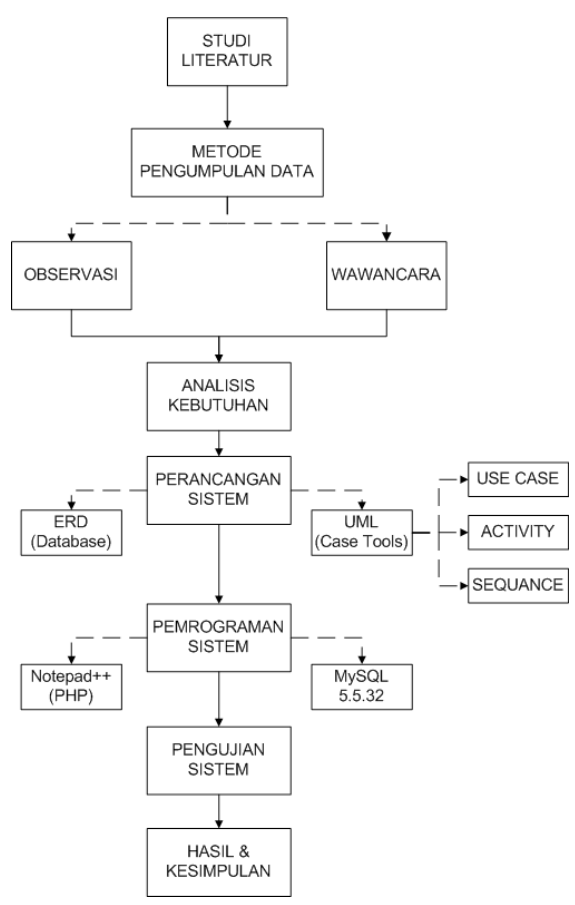

Gambar 1 Diagram Alir Penelitian 


\section{Perancangan Sistem}

Perancangan ini adalah sebuah proses mendefinisikan elemen sistem seperti modul, arsitektur, komponen dan antarmuka dan data untuk sistem berdasarkan persyaratan yang ditentukan. Ini adalah proses mendefinisikan, mengembangkan dan merancang sistem yang memenuhi kebutuhan spesifik dan persyaratan bisnis atau organisasi. Maka pada studi kasus berikut ini dibuat rancangan yang bertujuan untuk melakukan tahap awal dalam merancang suatu sistem.

1. Use Case Diagram, dalam diagram ini akan menunjukkan aktifitas kpala gudang mulai dari melihat data barang masuk, melihat barang keluar, memberi rekomendasi dan termasuk menambah staff gudang seperti gambar berikut ini

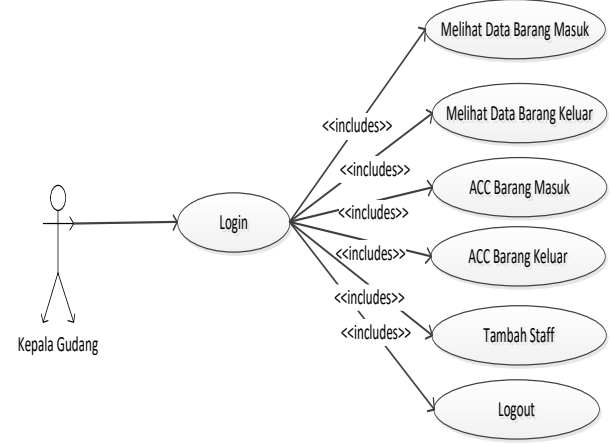

Gambar 2 Use Case Diagram Kepala Gudang

2. Use Case Diagram Staff Gudang

Kalau untuk staf gudang/bagian persediaan hanya akan melakukan pengelolaan/input barang masuk, barang keluar serta dapat menambah item yang akan dimasukkan dalam persediaan.

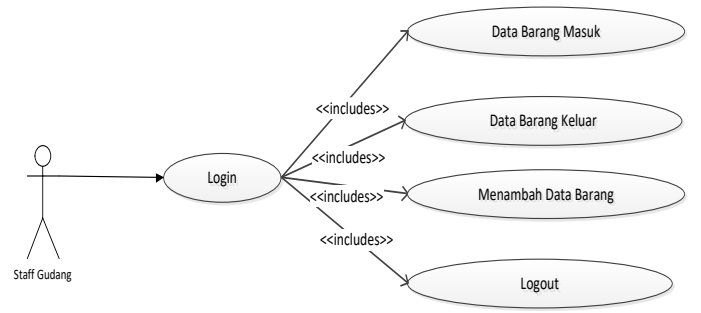

Gambar 3. Use Case Diagram Staff Gudang

3. Activity Diagram Akun Kepala Gudang di Website

Sedangkan aktifitas kepala gudang dalam aplikasi yang berbasis Website dapat digambarkan sebagai berikut:

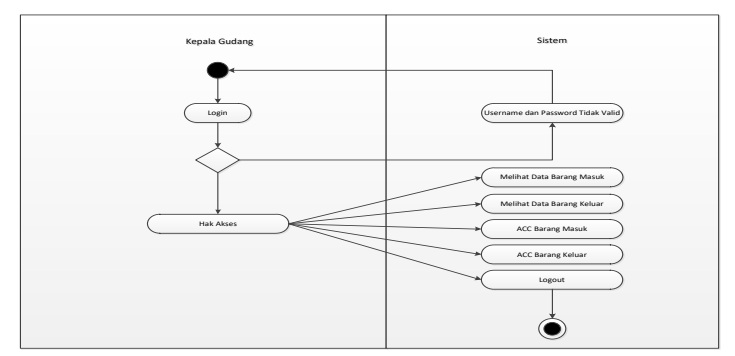

Gambar 4. Activity Diagram Akun Kepala Gudang di Website

4. Activity Diagram Akun Staff Gudang di Website

Sedangkan untuk bagian staff gudang aktifitasnya dapat digambarkan sebagai berikut:

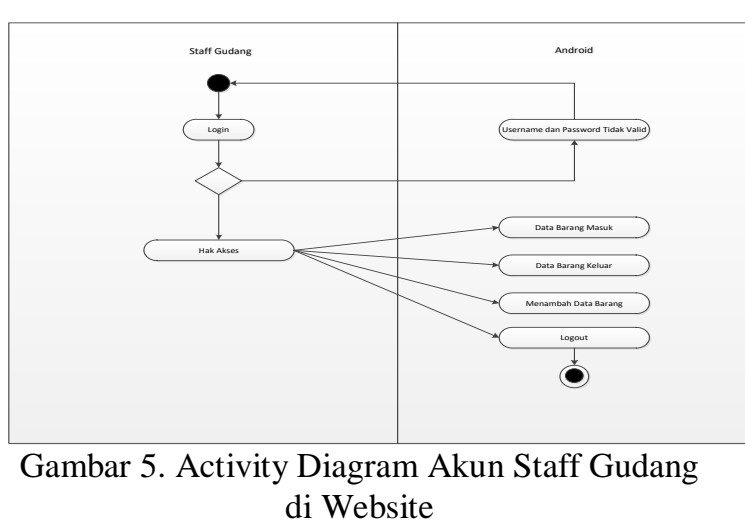

\section{HASIL DAN PEMBAHASAN}

Adapun interface dari hasil perancangan adalah dapat melakukan penambahan data barang, melakukan pencarian berdasarkan semua atribut barang, melihat rincian atau spesifikasi barang, kemudian dapat menampilkan informasi jumlah persediaan. Kemudian semua proses yang berhubunga dengan persediaan akan dikelola melalui aplikasi ini. Dapat dilihat pada gambar dibawah ini: 


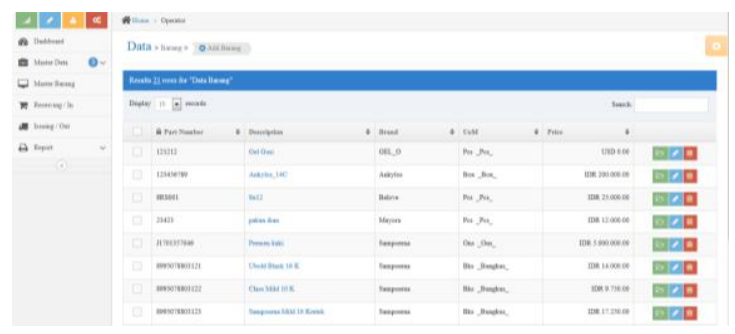

Dari hasil perancangan di atas menunjukkan bahwa pengelolaan persediaan dapat dikendalikan oleh bagian gudang. Dalam hal ini jumlah pengguna pada aplikasi diperbolehkan lebih dari satu sesuai dengan pengaturan hak aksesnya. Proses input dan pembuatan laporan juga dapat dilakuka melalui laman website yang dirancang. Sistem informasi persediaan ini adalah untuk melakukan pengelolaan yang baik, cepat dan akurat. Kemudian dapat melihat ketepatan perancangan stok, melihat kekurangan yang mungkin terjadi serta adanya kehilangan atau suatu pengendalian manajemen yang dilakukan oleh suatu perusahaan dalam mengetahui jumlah persediaan barang dan pekerjaan yang sedang berlangsung.

Maka hasil perancangan ini merupakan suatu sistem perangkat lunak yang berfungsi untuk melakukan proses inventarisasi seperti pencatatan data dari barang masuk sampai pada barang keluar, repair service konsumen dan pencatatan retur barang. Sistem informasi persediaan ini dilengkapi dengan sistem pelaporan seperti laporan - laporan internal perusahaan dan fitur approval yang sistematis dan akurat. Sistem informasi persediaan ini juga dibuat untuk beberapa pengguna yang memungkinkan pengaksesan sistem oleh beberapa pengguna yang berbeda dalam suatu waktu.

Pengujian pada sistem dilakukan dengan cara mengeksekusi pada unit atau modul yang dirancang, kemudian mengamati apakah hasil dari unit tersebut sesuai dengan proses bisnis yang dirancang serta yang diharapkan oleh perusahaan. Maka aspek fungsionalitas menjadi cara yang dilakukan dalam pengujian ini.

\section{PENUTUP}

Dari hasil pengujian dan pembahasan yang telah dibuat maka dapat disimpulkan dengan adanya monitoring persediaan barang di dalam gudang, mempermudah pelaku kepala gudang dan menager dalam memantau atau mengetahui persediaan barang masuk dan barang yang keluar dengan efektif setiap waktu kemudian aplikasi yang dibangun dapat memberikan kemudahan kepada Staff di dalam gudang untuk mengeluarkan dan memasukkan barang dengan menggunakan scan barcode tanpa harus mencatat barang secara manual.

\section{DAFTAR PUSTAKA}

[1] Ade Hendini. 2016. Pemodelan UML Sistem Informasi Monitoring Penjualan Dan Stok Barang (Studi Kasus: Distro Zheza Pontianak.) Pontianak AMIK BSI Vol. 4, No.2

[2] Andi Juansyah. 2015. Pembangunan Aplikasi Child Tracker Berbasis Assisted - Global Positioning System (A-Gps)Dengan Platform Website. Jurnal Ilmiah Komputer Dan Informatika (KOMPUTA) Edisi. 1 Volume. 1 ISSN : 2089-9033

[3] Assauri, S. 2016. Manajemen Operasi Produksi. PT .Raja Grafido Persada : Jakarta

[4] Efmi. 2018. Pemanfaatan Website Dalam Perancangan Aplikasi Kumpulan Doa. Bukittinggi : AMIK Boekittinggi

[5] Fridayhantie dan Eka Wida. 2016. Rancang Bangun Sistem Informasi Permintaan Atk Berbasis Intranet. Tangerang: AMIK BSI. Vol 4, No. 2

[6] Gata, Windu dan Gata, Grace. 2013. Sukses Membangun Aplikasi Penjualan dengan Java. Jakarta : Elex Media Komputindo.

[7] Harini. 2008. Penetapan Harga ,Makro Ekonomi Pengantar, Pt Gramedia.

[8] Herlina, A. \& Rasyid, P. M., 2016. Sistem Informasi Monitoring Pengembangan Software Pada Tahap Development Berbasis Web. Jurnal Informatika, 3(1).

[9] Jelita,Adam. 2017. Analisis User Interfacemedia Pembelajaran Pengenalan Kosakata Untuk Anak Tunarungu. Bandung : Issn : 2089-9033

[10] Kustiyahningsih, Yeni dan Devie Rosa Anamisa. 2011. Pemrograman Basis DataBerbasis Web Menggunakan PHP \& MySQL. Yogyakarta : Graha ilmu

[11] Manap, H. Abdul. 2016. Revolusi Manajemen Pemasaran. Jakarta: Mitra wacana media, 2016

[12] Nanang,Martono. 2015. Metode Penelitian Kuantitatif Teori \& Aplikasi. Jakarta: Rajawali Pers. 
[13] Siagian, Yolanda, M. 2005. Aplikasi Supply Chain Management dalam Dunia Bisnis. Jakarta: Grasindo

[14] Surawijaya dan Eko, 2017. Aplikasi Mobile Driver Online Berbasis Website Untuk Perusahaan Rental Kendaraan. Bandung : Universitas Komputer Indonesia. ISSN:2 